\title{
Sensibilidades jurídicas e respeito às diferenças: cultura, controle e negociação de sentidos em práticas judiciais no Brasil e em Timor-Leste
}

Legal sensitivities and respect to difference: Culture, control and meaning negotiation in judicial practices in Brazil and East Timor

\section{Daniel S. Simião}

\section{(2) OpenEdition Journals}

\section{Edição electrónica}

URL: http://journals.openedition.org/aa/1197

DOI: $10.4000 /$ aa. 1197

ISSN: 2357-738X

\section{Editora}

Programa de Pós-Graduação em Antropologia Social (UnB)

\section{Edição impressa}

Data de publição: 1 dezembro 2014

Paginação: 237-260

ISSN: 0102-4302

\section{Refêrencia eletrónica}

Daniel S. Simião, «Sensibilidades jurídicas e respeito às diferenças: cultura, controle e negociação de sentidos em práticas judiciais no Brasil e em Timor-Leste», Anuário Antropológico [Online], v.39 n.2 I 2014, posto online no dia 01 agosto 2017, consultado o 27 abril 2021. URL: http:// journals.openedition.org/aa/1197; DOI: https://doi.org/10.4000/aa.1197

\section{@(@) $\Theta \Theta$}

Anuário Antropológico is licensed under a Creative Commons Atribuição-Uso Não-Comercial-Proibição de realização de Obras Derivadas 4.0 International. 


\section{Sensibilidades jurídicas e respeito às diferenças: cultura, controle e negociação de sentidos em práticas judiciais no Brasil e em Timor-Leste}

Daniel S. Simião

UnB

\section{Justiça, reconhecimento e igualdade ${ }^{1}$}

Pesquisas feitas no Brasil acerca da judicialização de conflitos interpessoais têm indicado limites característicos de espaços judiciais para o equacionamento adequado da dimensão de reconhecimento que acompanha muitas das situações levadas a juízo. Mesmo espaços de relativa informalidade, como os juizados especiais, deixam reduzido tempo para a elaboração narrativa das histórias por trás das lides, reduzidas a uma lógica alheia a seu contexto original e marcada pelas representações que juízes e promotores têm acerca dos casos e das pessoas envolvidas. O mesmo vem ocorrendo em relação a casos de violência doméstica e familiar contra mulheres, em que pesem iniciativas localizadas de ampliação dos espaços de escuta e de contextualização das expectativas das partes em conflito.

Em pesquisa recente acerca da implantação da Lei Maria da Penha (11.340/2006) no Distrito Federal, pudemos observar uma experiência-piloto de atendimento multidisciplinar a casos de violência doméstica. ${ }^{2}$ Naqueles atendimentos, por mais que se buscasse construir um espaço de escuta prévio às audiências, as representações sociais que povoavam o olhar dos atendentes filtravam muito do que era dito pelas partes, fazendo com que a equipe multidisciplinar muitas vezes encapsulasse as mulheres na condição de vítimas e, mais que isso, na condição de incapazes de perceber adequadamente o que se passava com elas próprias (Simião et al., 2013). Em alguns casos, isso significava que a equipe e, posteriormente, o juiz deveriam proteger essa mulher contra sua própria vontade, ou contra a maneira pela qual ela mesma dava sentido às situações que vivia, em uma espécie de procedimento tutelar bastante conhecido da forma como o direito no Brasil lida com certos grupos sociais. Isso remete, diretamente, a um discurso que ouvi frequentemente em Timor-Leste, entre 2009 e 2011, por parte de operadores do direito, acerca da posição de mulheres e crianças, tida como vulnerável, em relação às formas culturalmente usuais de resolução de conflitos — um discurso que problematizo no filme Sé Mak Sala Tenkeser Selu Sala (Simião, 2012). 
Em outras ocasiões, mostrei que o recurso à polícia e ao tribunal é, em Timor-Leste, bastante incipiente (Simião, 2005b, 2011). Os muitos conflitos que surgem nas relações entre moradores de uma aldeia ou de um suku (unidade administrativa formada por um conjunto de aldeias no interior de um subdistrito) são em geral resolvidos localmente, por mecanismos tidos como "tradicionais". A literatura antropológica sobre essas formas locais de justiça tende a caracterizá-las como muito mais abertas à construção de soluções consensuais, enraizadas na perspectiva e na cosmologia das partes em conflito, tendo, portanto, maior capacidade de lidar efetivamente com a natureza dos conflitos em causa (Soares, 1999; Hohe \& Nixon, 2003; Williams-Van Klinken, 2003). Contudo, é comum ouvir, por parte dos operados do direito positivo, além de organizações de defesa de direitos, críticas ao que seriam os abusos da "cultura" contra grupos tidos como vulneráveis, sempre acompanhadas da ideia de que esse espaço culturalmente legitimado para resolução de conflitos deveria ser de alguma forma controlado pelo Estado (Simião, 2005b, 2011; Silva \& Simião, 2012). Isso me fazia (e ainda me faz) pensar em bons paralelos com a visão tutelar observada no Brasil, pela qual se retrata um tipo de sujeito como hipossuficiente e "merecedor" da tutela estatal.

Este artigo pretende explorar os limites dos sentidos de justiça e equidade em práticas judicializadas de administração de conflito que envolvem expectativas de reconhecimento moral, a partir de um olhar cruzado entre uma tradição de pesquisa no Brasil e recentes observações sobre dilemas semelhantes em Timor-Leste. Inspirado pelas reflexões de Luís Roberto Cardoso de Oliveira (2010) sobre o mundo cívico malconformado que vivemos no Brasil, pergunto-me em que medida o tratamento diferencial implica uma negação da dignidade das pessoas. ${ }^{3}$ Seria o critério da negação da dignidade um bom critério para avaliar a justeza ou adequação de uma prática de resolução de conflitos? Se sim, como os atores em conflito se sentem em relação ao modo como seu caso é tratado e como dão sentido a isso?

Para abordar esse tema, trago à reflexão a descrição etnográfica de um caso leste-timorense que nos permite colocar em perspectiva a visão (por vezes idealizada na literatura) acerca das formas locais de justiça e de sua sensibilidade jurídica (Geertz, 1983) como mais atentas às demandas por reconhecimento e sensíveis à dimensão moral dos conflitos. Com base na análise de um caso de resolução de conflito com desfecho trágico, proponho que não basta o espaço de enunciação de histórias para que ocorra o sentimento de justiça e reparação. Aponto para o papel central das práticas de compensação timorenses para dar conta da dimensão moral do conflito, estabelecendo, subsidiariamente, comparações com 
a sensibilidade jurídica brasileira e buscando caracterizar limites e possibilidades das chamadas "formas locais de justiça" em Timor-Leste, em especial em relação ao mundo cívico que as cerca. Evidencio ainda as diferenças que marcam o modo pelo qual a sensibilidade jurídica dessa forma de justiça lida com a dimensão moral dos conflitos, não sem relacioná-las a práticas e saberes judiciais locais.

\section{O caso}

Em 2013, permaneci dois meses imerso no cotidiano de uma aldeia timorense, nas montanhas do distrito de Liquiçá. Minha primeira surpresa, logo que comecei a pesquisa, foi perceber que os moradores da região consideravam os processos de resolução de conflitos feitos com intermediação do chefe de aldeia e chefe de suku como um recurso ao Estado. Os moradores entendiam que, quando levavam um caso ao suku ou à aldeia, apelavam ao Estado, uma vez que chefe de aldeia e de suku são figuras eleitas, empossadas pelo Estado e vistas como dotadas de abrigo legal para tal. ${ }^{4}$

Essa observação é importante, pois, na literatura e no campo discursivo de meus interlocutores em Díli, costuma-se opor a justiça feita nos tribunais — entendida como justiça promovida pelo Estado — às formas de mediação e adjudicação feitas nas aldeias, entendidas como "tradicionais", "costumeiras" e promovidas pela "cultura". Assim, a fronteira entre "tradição" ou "cultura" e "Estado" era subvertida pelas representações nativas que encontrei no suku. ${ }^{5}$ Com isso, não quero dizer que tal fronteira não exista, mas que ela toma configurações muito mais complexas que as de uma simples oposição definida a partir de uma perspectiva externa. O trânsito de práticas de controle e governo entre o mundo cívico das aldeias e aquele da administração central (ou "estatal”) em Timor é recorrente desde o tempo colonial português (Roque, 2011; Silva \& Simião, 2012), e a forma como as pessoas ressignificam tais práticas como próprias do "Estado" ou da "cultura" é ainda uma grande agenda de pesquisa para etnografias em Timor-Leste. ${ }^{6}$

No suku de Lisadila, onde tenho feito pesquisa, os conflitos são variados e frequentes. Em um intervalo de quatro semanas, assisti a quatro casos julgados e resolvidos por recurso a esse mecanismo "tradicional", sendo dois na sede de uma aldeia, um na sede do suku e um em nível familiar. Vou tratar aqui deste último caso, que envolveu um jovem casal de namorados, Arminda e Manoel.

Os dois namoraram por dois anos, tendo chegado a viver juntos por dois meses e fazer planos para se casarem. A mãe de Manoel, contudo, não concordava com o casamento, e fez o possível para evitar que as negociações entre as famílias fossem adiante. Em agosto de 2012, as famílias viram que não haveria 
negociação e decidiram que o casal deveria se separar. Como também não havia acordo sobre a melhor maneira de promover a separação, recorreram ao chefe de aldeia, que convocou anciãos, os lia na'in, para arbitrarem o conflito. $\mathrm{O}$ processo resultou em um acordo por meio do qual a família de Manoel deveria pagar uma multa à família de Arminda (materializada por um conjunto de bens, dos quais falarei adiante), e esta, para receber a multa, deveria dar outro conjunto de bens à família de Manoel.

O acordo foi feito, mas jamais foi implantado, pois a família de Manoel nunca se mostrava preparada para pagar o que devia. Cansada de esperar, a família de Arminda recorreu ao chefe de suku, que convenceu as partes de que a melhor solução seria uma mediação entre as próprias famílias, o que enfim ocorreu, no final de janeiro. Para essa mediação — feita na família, portanto vista, esta sim, como "tradicional" e não como recurso ao "Estado" — , as famílias chamaram cinco lia na' in: Júlio (lia na' in da aldeia de Glai, mas também da casa de Manoel e, nessa condição, rai na' in, o sujeito capaz de comunicar o resultado da mediação ao espírito da terra), Cirilo (lia na’in da aldeia), Guido (da casa de Manoel - Kailako Maubere), Camilo (da casa de Arminda - Beiliko Beikbau) e Estevão, uma espécie de tertius, pois não pertencia àquela aldeia nem às casas em questão.

Seguindo o protocolo dessas formas de mediação, que em geral tomam um dia inteiro, as partes entregaram aos lia na' in porções de noz areca e folhas de betel, a serem oferecidas aos ancestrais. Os lia na'in ouviram as narrativas das partes, conversaram entre si e, inspirados pelos ancestrais, chegaram a um entendimento sobre como o problema deveria ser resolvido. A família de Manoel deveria pagar uma multa, entregando à família de Arminda quatro peças de tais (o tecido tradicional timorense) e quatro porcos. Teria ainda que providenciar 24 dólares, para pagamento aos lia na’in, cerveja para a cerimônia de paz e um animal, a ser sacrificado para o espírito da terra durante essa cerimônia. $\mathrm{O}$ animal serviria ainda de oferenda aos ancestrais das casas em questão, bem como das casas dos próprios lia na'in.

Contudo, como é comum nesses processos, a família de Arminda não poderia apenas receber. Tinha que dar algo em troca. Justifica-se isso dizendo que, se apenas uma parte é condenada a dar, ela pode ficar ressentida, o que impede a manutenção da boa relação entre as casas. Ao mesmo tempo, receber sem dar nada em troca pode ser motivo de vergonha e humilhação para quem recebe. A preocupação com a manutenção dos vínculos, estabelecidos pelo regime da dádiva, é central para o bom equacionamento de conflitos em relações de proximidade. Assim, a família de Arminda teria que entregar, como contradádiva, um disco dourado (belak mean), além de providenciar para os lia na' in o montante de Anuário Antropológico/2013, Brasília, UnB, 2014, v. 39, n. 2: 237-260 
24 dólares e pagar aos lia na' in uma multa de 20 dólares, a título do que se chama mutin ho mean. ${ }^{7}$ Teria ainda que prover cerveja para a cerimônia de paz e um saco de arroz para ser cozido com a carne do animal sacrificado durante a cerimônia.

A materialização da pena em bens a serem trocados entre as partes opera uma diferença significativa em relação ao que seria, na lógica do direito positivo, uma indenização por danos morais. Os bens trocados em um processo de reconciliação como o aqui descrito não podem ser comutáveis em dinheiro. Os porcos e as peças de tecido da família de Manoel que seriam oferecidos como "compensação" para a família de Arminda não têm equivalente monetário.

Há, ao menos, dois níveis de explicação para isso. De acordo com os lia na’ in com quem conversei, são tais bens, e não outros, que a "cultura" manda serem ofertados. Isso porque Manoel está na posição de quem se separa de uma esposa, o que o obrigaria a devolver os bens recebidos durante o casamento - e a família do noivo sempre recebe porcos e tecidos por ocasião do casamento. Assim, o conflito é enquadrado pelo idioma das prestações matrimoniais, altamente prescritivo e mediado por bens com significados específicos. ${ }^{8}$

Em um nível mais profundo, os bens trocados carregam a própria natureza da relação entre as partes, bem como a posição de cada uma delas. Não é apenas a troca de bens que representa uma relação, mas a natureza dos bens trocados que indica a natureza da relação em si. Como já dito acerca da Melanésia, pessoas e relações são, aqui, indissociáveis (Strathern, 1991; Wagner, 1991), sendo a própria pessoa constituída pelas relações que estabelece com outras. Assim, podemos dizer que as coisas trocadas, mais do que representar, são, de fato, as relações e, por conseguinte, são também as pessoas. Não por acaso, é dessa região do mundo que vem o material etnográfico que permite a Mauss (1974) desenvolver a ideia - central em sua teoria da dádiva — de que as coisas dadas levam consigo algo de quem as deu, o seu hau. A palavra hau, aliás, em várias línguas austronésias (como é o caso do tétum), significa simplesmente "eu”. Quero propor com isso que a coisa ofertada faz mais do que levar uma "substância" de quem a oferta. A coisa é a pessoa que a oferta, na medida em que sua natureza materializa a posição de pessoa em jogo em uma relação. A coisa constitui a posição de pessoa; e a troca, ao materializar uma relação, constitui a própria pessoa (ao menos naquela circunstância). ${ }^{9}$

A troca materializada por bens incomutáveis assume, assim, um sentido de reconhecimento (Honneth, 1996; Taylor, 1994) tanto da existência social da pessoa (das pessoas, de fato, já que ambas têm algo a dar), por meio de uma relação consubstanciada nos bens trocados, como do tipo de pessoa-relação, evidenciado na natureza dos bens. Os bens trocados como "compensação" em uma 
cerimônia de reconciliação expressam, pois, muito mais do que o pagamento de uma indenização a alguém ofendido - como seria o caso da indenização por danos morais, no direito positivo. Além disso, ao se dar no contexto de uma troca (para receber os porcos e tecidos, mesmo que a título de compensação, a família de Arminda tem que reciprocar com um disco dourado), a "compensação" pressupõe um ideal de restabelecimento de uma relação entre as partes. As famílias poderiam, depois do ritual, voltar a conviver normalmente.

Curiosamente, isso parece levantar obstáculos a um dos discursos observados entre operadores do direito em Timor-Leste que busca justamente aproximar as formas de resolução de conflitos vigentes nas aldeias da prática patrocinada pelos tribunais. Para esses atores, as "duas" formas de justiça (a do "Estado" e a "tradicional”) têm pontos de contato e devem ser integradas em um único sistema, ao contrário da tradição colonial (em especial britânica) de manter uma justiça "nativa" para os "nativos" e outra para os europeus e "assimilados". No documentário Sé Mak Sala Tenkeser Selu Sala (Simião, 2012), tal discurso é mais evidente nas falas da juíza administradora do Tribunal Distrital de Díli e, especialmente, da procuradora-geral da República. Esta menciona explicitamente a indenização por danos morais como equivalente às compensações arbitradas nas aldeias. Parece-me, contudo, que os sentidos de reparação em causa não podem ser equiparados, dado o sentido muito particular das coisas trocadas nos rituais locais, bem como sua relação com a própria concepção de pessoa e de eu (hau) — concepção, também ela, diferente daquela do "indivíduo" jurisdicionado pela corte estatal.

Nesse contexto, não é de estranhar que a definição sobre a natureza e a quantidade de coisas envolvidas nas trocas que materializam as sanções dependa: 1) da natureza da relação entre as partes (se as famílias tinham uma relação prévia estabelecida por redes de casamento); 2) da natureza do conflito (se era percebido como ofensa mais ou menos grave); e 3) da posição de cada parte em algum dos vários sistemas de prestígio que operam na aldeia.

No caso de Arminda, como vimos, a natureza da relação implicava que a família de Manoel "devolvesse” bens usualmente dados pela família da noiva em um casamento (porcos e tecidos), e a de Arminda, bens usualmente dados pela família do noivo (o disco dourado). Com relação ao sistema de prestígio operante, este dizia respeito ao valor das casas. A casa de Arminda (Beilik Beikbau) não era uma casa qualquer, mas a segunda casa real do suku. Havia sido a casa do régulo do suku, ainda no tempo da dominação portuguesa. Ainda assim, a natureza do problema não era tida como grave: Arminda não estava grávida, e poderia futuramente se casar com outro homem. Assim, o montante envolvido na multa 
não era grande e, principalmente, a carne a ser oferecida aos ancestrais não seria a de um cabrito, como de costume; bastaria um pato.

Ainda sobre a definição das penas, esse não é um processo simplesmente racional, de aplicação de um código invariável. Os lia na’ in são acompanhados pela presença invisível de seus ancestrais e decidem o caso inspirados por eles. Por isso, durante o julgamento e na cerimônia de reconciliação, é preciso haver oferendas (areca e betel, bebida, carne e arroz) a serem levadas, posteriormente, às casas sagradas de cada lia na' in como dádiva a seus ancestrais. O processo é todo marcado pela cosmologia religiosa local. É claro que nossos julgamentos, no Brasil, também estão marcados por um registro religioso (um crucifixo na sala de audiência, uma Constituição promulgada “sob a proteção de Deus" e, mais recentemente, juízes que incluem em suas sentenças referências diretas a Deus e à religião). Contudo, a sensibilidade jurídica timorense assume-se explicitamente como inscrita nessa cosmologia, sendo impossível fazer um julgamento sem ela.

Depois de concluído o julgamento, marcou-se, para dali a uma semana, a cerimônia de paz ho dame. ${ }^{10}$ A cerimônia, como de costume, durou uma tarde inteira. No início, dois lia na' in, incluindo o rai na' in, separaram em uma pequena cesta as folhas de betel, as nozes de areca e a bebida, e, levando a cesta e um pato, partiram para um lugar específico, sagrado, para comunicar o acordo ao espírito da terra. No local sagrado, as orações foram feitas, e o pato, sacrificado. Após o retorno, todos os lia na' in recapitularam o caso, materializando em palavras todos os movimentos dados até ali, o que consumiu quase uma hora. Enquanto isso, o pato era preparado na cozinha.

As partes trouxeram os bens que deveriam trocar. Sempre acompanhados de longas narrativas dos lia na' in, os bens foram trocados. A cada troca, apertos de mão selavam a paz. Depois de trocados os bens e recolhido o dinheiro, que ficaria com os cinco lia na'in, uma nova sequência de discursos teve lugar. Cada lia na' in reforçava o sentido das sanções aplicadas, ressaltando a importância de que aquele tipo de problema não voltasse a ocorrer na aldeia. Eventualmente, algum dissenso transpareceu na fala dos pais dos jovens, silenciado pela fala longa, enfática e cheia de autoridade do lia na'in da casa de Arminda, senhor Camilo. Desta vez, o chefe de aldeia, senhor Ventura, também discursou, reforçando os pontos marcados por Camilo. Na sequência, Arminda entregou a Manoel os poucos objetos pessoais deste que ainda estavam em sua casa. Ao final, um brinde cerimonial, em que as partes bebiam do mesmo copo, selou a paz. Todos se abraçaram efusivamente.

Com o pato preparado, todos comeram. Uma parte da carne foi separada em pequenas cestas, com arroz, areca e betel, para ser levada à casa sagrada dos lia 
na' in. O evento terminou por volta das $18 \mathrm{~h}$, quando me retirei. Às $20 \mathrm{~h}$, o pai de Arminda, senhor Valente, acompanhado de um tio da jovem, foi à sua casa sagrada para levar as oferendas e fazer as orações necessárias a selar definitivamente a paz. Quando entraram na casa, porém, depararam-se com o corpo de Arminda, inerte, suspenso por uma corda. A jovem havia acabado de se enforcar, dentro da casa sagrada.

A polícia, que por sorte estava fazendo ronda em Lisadila naquela noite, foi avisada e isolou a área. Na manhã seguinte, o suku estava em polvorosa. Assim que Manoel chegou ao lugar, o pai de Arminda partiu para cima do jovem, aos gritos, e começou a agredi-lo, culpando-o pela morte da filha. Se a polícia não estivesse presente para separá-los, teríamos ali outra morte. O problema que havia sido "pacificado" no dia anterior agora se desdobrava em dimensões ainda maiores.

Durante o dia, conversei com vários de meus interlocutores sobre o ocorrido. Todos comentavam que a jovem se matara por não querer viver sem seu amor, o que, aliás, consideravam uma bobagem incompreensível. Cheguei mesmo a comentar com alguns que aquilo me parecia um gesto de protesto de Arminda contra uma decisão que não contemplou seu desejo. Um ritual marcado por longas narrativas e no qual a palavra tem um lugar central (afinal, lia na' in quer dizer, literalmente, o homem das palavras) acabou anulado por um único e supremo gesto — e este, em um minuto, desfez o que mil palavras haviam feito.

No dia seguinte, fui conversar com os pais de Arminda. Queria ouvir sua interpretação do fato. Lá estava também Camilo, que atuara no processo como lia na' in da casa da jovem. Comovido, ele falava com lágrimas nos olhos. Disse que haviam errado no procedimento, e por isso o caso tivera um desfecho trágico. O grande erro, segundo Camilo, foi terem acertado que bastaria sacrificar um pato na cerimônia, em lugar do usual cabrito. Aquela não era uma casa qualquer, e o sacrifício do pato certamente irritara os ancestrais da casa, que, para lavar sua honra, vieram buscar a jovem — e não por acaso ela morreu na casa sagrada, a casa dos ancestrais. A interpretação de Camilo surpreendeu-me. Era, contudo, absolutamente lógica, e evidenciava a força dos saberes locais na produção de uma interpretação razoável para o ocorrido.

Segundo esse modo de ver as coisas, a agência não está na pessoa (Arminda), mas nos ancestrais. Temos aqui um enquadramento cosmológico no qual a ideia de indivíduo não opera fortemente na construção da subjetividade. O pai de Arminda, senhor Valente, ainda mais desolado, limitava-se a aquiescer com a cabeça. Quando interpelado por mim, reforçou a interpretação de Camilo, mas com um comentário que matizava a não agência de Arminda. Segundo Valente, 
a filha havia se sentido humilhada com o fato de seu caso ser resolvido com o sacrifício de um simples pato. Ela teria comentado isso várias vezes dentro de casa, ao longo da semana que antecedeu a cerimônia. A vergonha e a humilhação teriam contribuído para que ela perdesse o desejo de viver.

No mesmo dia, levei essas interpretações a outro dos lia na' in envolvidos no processo, senhor Estevão, meu interlocutor desde 2009. Estevão não concordava com a interpretação dada por Camilo. Segundo ele, a definição da carne do sacrifício é atribuição dos lia na'in, e não cabe aos ancestrais opinar sobre ela. Tínhamos aqui outra disputa sobre as agências envolvidas no processo. Afinal, nem tudo estava nas mãos dos ancestrais, e haveria limites para o juízo que eles podiam fazer acerca das ações dos vivos. Para Estevão, o processo não fora falho. A mediação não permitia aos lia na'in se sobrepor à vontade das famílias. Como uma das famílias se mostrava irredutível pela separação, coube aos anciãos definir a maneira correta de fazê-la. Para Estevão, Arminda havia sim decidido se matar, e o fizera porque não aceitara a obstinação da mãe de Manoel em separá-los. Separada de seu amor, não via mais sentido na vida.

A variedade de interpretações para o fato é algo sobre o que pensar. É verdade que há um enquadramento cosmológico no qual a ideia de indivíduo e a ideologia individualista, no sentido dumontiano, não opera (Dumont, 1985). É difícil depreender que tipo de subjetividade esse enquadramento conforma e produz. É possível mesmo que Arminda não tenha propriamente decidido se matar como forma de, enfim, fazer ouvir sua vontade. É possível que se sentisse envergonhada e tenha mesmo ouvido (ou pensado ouvir) algum chamado ancestral. Socializada em um ambiente em que a agência sobre a vida e a morte, a saúde e a doença, é sempre objeto de compartilhamento e negociação entre vivos e mortos, não seria de estranhar que Arminda tenha se deixado levar pelos ancestrais. O que, realmente, passou pela sua cabeça, não saberemos. Nem creio que seja esse o foco de uma interrogação antropológica, preocupada antes com os discursos e as interpretações socialmente partilhadas. Quero, contudo, sublinhar o desafio de levar em conta os processos de individuação e construção de subjetividades que me parecem fundamentais para se dar conta do sentido que os atos podem ganhar para um sujeito, o que inclui localizá-los como atitude de insulto ou desconsideração.

Ao comentar o caso com uma amiga estrangeira, em Díli, já na véspera de meu retorno ao Brasil, ouvi novamente a crítica à inadequação das formas locais de resolução de conflitos para alcançar soluções justas para com mulheres e crianças, acompanhada, como de costume, pela avaliação de que o Estado deveria tutelar o direito desses grupos, tidos como vulneráveis. Embora o desfecho 
trágico do processo me tenha feito concordar, no momento, com as críticas de minha amiga, creio que há mais o que dizer sobre isso. E, para fazê-lo, tenho que retomar o início deste texto. Antes disso, porém, devemos entender melhor o que esteve em jogo nessa tragédia.

\section{Romeu, Julieta e a dimensão moral do direito}

Seja qual for a interpretação que escolhamos para a morte de Arminda, o evento parece apontar para algum nível de demanda de reconhecimento moral. Na interpretação de Estevão e de Valente, trata-se de uma demanda de reconhecimento feita pela jovem: seja o reconhecimento de sua vontade de viver com Manoel, seja o reconhecimento do valor de sua casa. Na interpretação de Camilo, a demanda é feita pelos ancestrais. De qualquer forma, o gesto supremo da jovem comunica aos demais uma reivindicação não atendida - e possivelmente sequer percebida como tal até o momento da tragédia. Nesse sentido, parece-me plausível interpretar essa tragédia como um caso de demanda moral não resolvida por um mecanismo de justiça tido, na literatura, como capacitado a fazê-lo.

A atenção dada em rituais de reconciliação como o aqui descrito às posições das partes, à natureza de sua relação e à natureza do caso em si é aspecto fundamental da sensibilidade jurídica operante nas aldeias e sukus timorenses, prescrito e afirmado como um imperativo. Em tese, isso torna tais modelos mais sensíveis a demandas de reconhecimento, que exigem a atenção dos operadores do caso à forma como as partes entendem suas trajetórias. Isso também contrasta com a dificuldade observada no sistema jurídico brasileiro (e em geral no modelo civilista, como é a justiça dos tribunais em Timor-Leste) em incorporar a dimensão moral dos conflitos.

Ao ser judicializado, um caso que envolva pessoas em relação de proximidade perde sua natureza original para se tornar, por meio da redução a termos, uma lide judicial. Vários autores já chamaram atenção para o fato de esse movimento excluir do processo judicial elementos do conflito tidos como centrais para as partes em litígio, tais como o contexto que deu origem ao conflito, bem como os sentimentos das partes em relação ao mesmo (Cardoso de Oliveira, 2002; Kant de Lima, 2008). A distância entre a forma como o Judiciário vê o caso (a lide) e o modo como as partes vivenciam o conflito tende a gerar, entre elas, um sentimento de injustiça ou desconsideração. ${ }^{11}$

A forma como se estrutura a sensibilidade jurídica ocidental, moldada por relações contratuais entre partes e fundada na ideia de produção material de provas, torna o processo judicial impermeável àquilo que Cardoso de Oliveira (2002, 2008) define como "insulto moral". De difícil materialidade, por envolver uma 
dimensão subjetiva por parte de quem a sente, a ofensa causada pela percepção de um insulto moral muitas vezes não encontra meios, no Judiciário, para ser adequadamente reparada. No caso das formas locais de justiça em Timor-Leste, esperava-se que, ao atentar para a natureza do conflito e disponibilizar meios de materializar (pelas trocas de bens e de palavras) o reconhecimento da ofensa, essa dimensão moral fosse mais facilmente contemplada.

A questão que se põe, então, é se podemos tomar a morte de Arminda (e os conflitos dela decorrentes) como um exemplo de "fracasso" desse mecanismo de reparação - um alerta sobre os seus limites. Para enfrentar essa questão, proponho mudar o foco do que tem sido percebido como característica própria desses mecanismos na literatura regional. Parece-me que o que está no centro de tais mecanismos não é, como se costuma enfatizar na literatura (em especial a de inspiração estruturalista na região), o restabelecimento do equilíbrio comunitário. O ponto central em jogo nesse processo — daí a centralidade das trocas de bens no ritual - é a afirmação de posições de pessoa em relação. O que se estabelece com tais rituais é, antes de tudo, a "dignidade" das pessoas construídas por meio das trocas em causa.

Por dignidade devemos entender não a categoria que, no Ocidente, veio a ocupar o lugar da honra na passagem do ancien régime para a modernidade (Berger, 1983; Taylor, 1994), mas sim o sentido nativo abundantemente usado em Timor-Leste, marcado pelas características próprias da honra. Ter "dignidade", em Timor-Leste, é ter sinais de distinção e ser tratado de acordo com a posição de pessoa que se conquistou. Assim, durante um processo de mediação ou arbitragem, as partes lutam por ver-se inscritas em posições de pessoas tidas como honradas, e o que o ritual faz, menos do que restaurar um ideal de equilíbrio social, é restaurar a pessoa-relação — ou a "pessoa fractal”, no dizer de Wagner (1991). As trocas, aqui, são o único meio de reconstruir uma posição de pessoa em uma relação, sem o quê não há pessoa possível.

Não se trata, assim, de repor um equilíbrio abstrato entre grupos, mas de pavimentar um caminho para a identificação das pessoas e de sua "dignidade". Isso torna o processo bastante sensível à dimensão moral, para lidar não apenas com a percepção de insultos morais, mas também com um grande potencial para produzir tais insultos. O registro da dádiva mostra-se aqui bastante traiçoeiro, uma vez que uma palavra mal colocada ou um bem mal avaliado podem ser tão ou mais ofensivos do que a situação que originou o processo. Parece-me que, no caso de Arminda, o modo pelo qual o processo se desenrolou levou à percepção, pela jovem, de um grande insulto moral. 
Seguindo-se a interpretação dada por Valente, pai de Arminda, podemos dizer que a natureza do animal sacrificado teria sido lida pela jovem na chave que rege a interpretação dos bens trocados. A natureza do animal - um pato - comunicava uma posição pouco prestigiada para a pessoa da jovem. Ao oferecer um pato, e não um cabrito, a família de Manoel inscrevia Arminda em uma posição de pessoa de menor valor em relação aos demais, de certa forma afetando sua "dignidade". Nesse sentido, a oferta do pato teria certamente motivado um sentimento de insulto moral — não percebido como tal, contudo, pelos lia na' in e não verbalizada como tal pelos pais de Arminda durante a cerimônia. O mesmo movimento pode ser observado se seguirmos a interpretação do lia na' in Camilo. A diferença é que, nesse cenário, os verdadeiros insultados teriam sido os ancestrais da casa Beilik Beikbau, que teriam vindo buscar Arminda naquela noite para lavar sua honra. O pato inscreveria a casa (e não apenas Arminda) como unidade moral, em uma posição de menor valor relativo.

Resta, ainda, a interpretação de que Arminda teria se matado por amor até onde pude acompanhar, a mais partilhada no suku, ao menos nos dias que se seguiram ao evento. Nesse sentido, poderíamos entender seu enforcamento como um ato de desespero diante do sofrimento gerado por não poder fazer valer sua vontade. A negação de seu desejo teria gerado uma situação insuportavelmente insultante para ela, mas não suficiente para gerar indignação entre os homens do suku, que consideravam esse tipo de sofrimento uma bobagem incompreensível. ${ }^{12}$ As condições para que o sofrimento de Arminda gerasse compaixão nos demais dependeriam de um enraizamento local do ideal de amor romântico, aparentemente ausente pelas reações que pude observar.

Nos eventos públicos que acompanhei depois da morte de Arminda, era chocante ver como os homens do suku (tanto mais velhos quanto mais jovens) riam e faziam piadas com o enforcamento da jovem. Eles achavam incompreensível que alguém se matasse “por amor”. De fato, os únicos a demonstrar sofrimento e pesar com a morte da jovem eram seus familiares diretos. O gesto da jovem, lido nesse registro, parecia fugir completamente ao que seria uma conduta razoável aos olhos do grupo, ganhando tons de loucura.

É impossível deixar de fazer aqui um paralelo com Romeu e Julieta, de Shakespeare, e com as muitas heroínas de óperas do século XIX que, impedidas de viver seus grandes amores, protagonizavam célebres "cenas de loucura". ${ }^{13} \mathrm{O}$ amor romântico depende de uma moralidade impregnada pela ideologia individualista - sem o quê os leitores de Shakespeare ou o público das óperas dificilmente se identificariam com o sofrimento dos heróis e das heroínas dessas tragédias. A "loucura" de Arminda, por outro lado, é despida de qualquer valor virtuoso Anuário Antropológico/2013, Brasília, UnB, 2014, v. 39, n. 2: 237-260 
em Lisadila, sendo vista, por boa parte de seus conterrâneos, como risível e sem sentido.

Ao se adotar esta última interpretação, estaremos, aparentemente, em uma situação na qual diferentes subjetividades implicam uma diferente percepção da ofensa. Elementos da ideologia individualista certamente estão presentes na percepção dos moradores do suku acerca do sofrimento de Arminda, do contrário a interpretação de que alguém possa tirar a própria vida por amor sequer seria levantada. Contudo, tais elementos não são fortes a ponto de tornar o amor romântico um ideal valorizado no grupo. Nessa leitura, por maior que fosse o sofrimento de Arminda, esse sentimento não gozaria de legitimidade social a ponto de gerar, nos atores à sua volta, a indignação que a percepção de um insulto a alguém gera em um terceiro que o presencia.

Com isso, parece-me impossível compreender a localização de um ato como insulto ou desconsideração sem levar em conta os complexos jogos de individuação e construção de subjetividades nos quais sujeitos concretos estão inseridos. Os processos de subjetivação (a maneira pela qual um sujeito entende a si mesmo no mundo à sua volta) operantes no local parecem-me cruciais para definir o sentido que os atos podem ganhar para um sujeito. Isso torna também difícil entender o que pode ou não ser percebido como afronta à dignidade de um sujeito em contextos particulares.

Lida na ótica de qualquer das três interpretações acima, a tragédia de Arminda parece mostrar que, para o equacionamento justo de demandas morais, não basta um sistema capaz de ouvir ou incorporar sentimentos e moralidades. A sensibilidade jurídica local estava aberta a isso. Contudo, justamente por colocar o regime da dádiva em posição central (com seus delicados mecanismos de avaliação de bens e palavras na constituição de pessoas), o ritual de reparação mostrou-se igualmente capaz de produzir o insulto. Ao mesmo tempo (e para complicar a equação), esse processo é acionado em um contexto no qual diferentes processos de subjetivação operam na construção dos sentimentos. Não estamos falando de uma aldeia alheia a processos de modernização, mas de um universo que convive com valores como o do amor romântico ao lado do respeito à agência dos ancestrais e de suas casas. ${ }^{14}$ Isso torna difícil a construção de uma base compartilhada para a interpretação dos sentimentos individuais.

\section{Conclusões}

Para concluir, voltemos ao início deste texto, em que se colocava a questão da justeza ou equidade na resolução de conflitos a partir da tutela de direitos, tal como observado nos casos de violência doméstica no Distrito Federal. Assim 
como Arminda pode ter incorporado um modo de ver e sentir o mundo pelo qual o pato representa maior ofensa do que a separação em si, ${ }^{15}$ vemos, no Distrito Federal, vários casos de mulheres que incorporam como natural uma rotina de xingamentos e agressões do marido, tomando como ofensivos outros comportamentos (a agressão a um filho, por exemplo). Casos como esse preocupam os profissionais do atendimento e levam a atitudes tutelares que desconsideram as demandas originais das mulheres (Simião et al., 2013).

A ideia de que a persecução criminal, sob certas circunstâncias, está acima da vontade individual da mulher é consagrada na interpretação da lei brasileira de combate à violência contra a mulher (Lei Maria da Penha, 11.340/2006), que considera casos de lesão corporal como objeto de ação pública incondicionada. Isso acaba por retirar das mãos da mulher um mecanismo de pressão e controle sobre a conduta do parceiro antes usual - a de ameaçar com uma denúncia, mas manter nas próprias mãos a possibilidade de retirá-la. Pasinato (2004) e Amorim (2007) já indicavam, há alguns anos, o sentido desempoderador dessa interpretação para muitas mulheres. Esse esvaziamento da agência individual (da mulher) em favor de um agente abstrato (o Estado, via Ministério Público) justifica-se, no histórico de elaboração e interpretação da Lei Maria da Penha, pela pressuposição de um universal de dignidade a ser preservado por meio da tutela estatal, nem sempre conhecido ou compreendido pelas mulheres que recorrem à justiça, mas tomado como dado pelas organizações de defesa de direitos.

Sob essa ótica, poderíamos dizer que Arminda não fora adequadamente "protegida" pelos responsáveis pela reconciliação — não teve resguardada sua "dignidade", seja no sentido timorense, de honra, seja no ocidental —, e isso resultou em uma tragédia. Os casos do Distrito Federal indicam, por outro lado, que tal "proteção" também pode significar a desconsideração dos sentimentos e desejos das mulheres que recorrem à autoridade judicial. Retomamos assim o desafio analítico com o qual comecei este artigo. Em que medida uma proteção mandatória representaria o atendimento a demandas morais dessas mulheres ou, ao contrário, um ataque à sua dignidade?

A discussão dessa questão passa pelo entendimento de um universo compartilhado de normas e valores relativos a direitos internalizados pelas partes em conflito - um mundo cívico mais bem ou mais mal conformado, como diria Cardoso de Oliveira (2010). Parece que, nas aldeias em que pesquisei, temos não um, mas ao menos dois mundos cívicos sobrepostos: um governado pelas obrigações com as casas e seus ancestrais, e outro marcado pela presença do Estado e pelo universo dos direitos individuais, embora lidos de maneira muito particular. A controvérsia acerca do significado da morte de Arminda sugere 
que, no mundo cívico governado pelos ancestrais e pelas obrigações entre as casas, as normas não são tão consensuais e claras quanto a literatura etnográfica predominante na região parece indicar — o que torna complicado definir o que pode ou não ser tomado como afronta à dignidade de uma casa ou de uma pessoa. Na definição do pato como animal sacrificial, não ocorreu aos lia na' in que isso pudesse ser tomado, pelos ancestrais, como ofensivo. ${ }^{16}$ Da mesma forma, não lhes pareceu que a separação do casal pudesse gerar um sofrimento insuportável à jovem.

Por outro lado, o simples sequestro dos casos desse universo de normas para o universo do mundo cívico regido pelos códigos do Estado dificilmente responderia adequadamente às demandas e aos sentimentos vividos por essas pessoas. Em outro texto (Simião, 2011), já observei que a redução dos conflitos construídos sob lógicas e valores vigentes no universo das aldeias para a lógica dos códigos e valores judiciais pode trazer ainda mais prejuízos às mulheres envolvidas em tais processos. ${ }^{17}$ Em um contexto no qual operam diferentes formas de subjetivação, torna-se difícil avaliar o que poderia ser tomado como um critério de justiça aos olhos das partes envolvidas. Nessas condições, submeter tais sujeitos a uma sentença que lhes é alheia, sem um esforço argumentativo capaz de convencê-los da validade da mesma, não deixa de ser outra forma de violência - estatal, no caso. ${ }^{18}$

Tendo a crer que essa sobreposição de formas de subjetivação não é exclusividade timorense. A levar a sério a ideia de um mundo cívico malconformado, vemos que no Brasil também operam distintos registros para o que seria socialmente aceitável em termos de expressão de condutas e sentimentos respeitadores da equidade no espaço público. Não há por que não supor que tais registros produzam diferentes formas de subjetivação. No caso da violência contra a mulher, aliás, parcela significativa dos movimentos feministas e de mulheres busca, desde as últimas décadas do século XX, difundir entre diferentes setores da sociedade — não sem grandes dificuldades ${ }^{19}$ — uma subjetividade específica, pautada pela noção de indivíduo como valor central. O problema emerge quando essa subjetividade ideal se cristaliza em uma ação legal, atravessada pelas práticas judiciais brasileiras — cartoriais e inquisitoriais, como as etnografias da área indicam. Nesse contexto, a redução de sentimentos, desejos e socialidades à lógica de um único universo valorativo ao qual se associa um conjunto limitado de demandas morais legítimas (uma mulher pode expressar insatisfação com seu companheiro, mas não o desejo de continuar em uma relação marcada por uma sociabilidade lida, de fora, como violenta) pode resultar na percepção de graves injustiças pelas próprias mulheres, seja em Timor-Leste, seja no Brasil. 
A questão norteadora deste texto (em que medida uma proteção mandatória representaria o atendimento a demandas morais dessas mulheres ou, ao contrário, um ataque à sua dignidade) poderia receber uma resposta bem timorense: conforme. ${ }^{20}$ Menos do que o respeito a um valor externo absoluto, o atendimento a expectativas de justiça dessas mulheres passaria pela percepção adequada dos sentidos de "dignidade" em causa e do grau de compartilhamento dos mecanismos de subjetivação operantes na socialidade entre as partes. ${ }^{21}$ Nesse sentido, a própria judicialização dos conflitos em relações persistentes e de proximidade mostra-se limitada para alcançar soluções percebidas como justas ou equânimes. ${ }^{22}$ Em que medida, porém, a judicialização pode ter um potencial "pedagógico" para a transformação de condutas tidas como aceitas em tais relações é uma questão em aberto.

De qualquer forma, creio que, quando tratamos de sentimentos, estamos em um terreno para o qual a antropologia precisa aprimorar seus instrumentos de pesquisa. Não creio que se possa fazer uma análise adequada do que seria percebido como ofensa ou indignidade por alguém sem levar em conta as condições de individuação e subjetivação da experiência pela qual esse alguém passou. Relembrando Mauss (1974), não estamos falando apenas do "direito", nem tampouco "do melanésio de tal ou qual ilha". Estamos falando do modo pelo qual esse melanésio (ou essa austronésia, no caso, Arminda) inventou a si mesmo, negociando seu pertencimento a diferentes universos normativos e procurando inscrever sua vontade e seus sentimentos dentro (ou para além) dessas normatividades.

Recebido em: 05 de julho de 2014

Aceito em: 25 de agosto de 2014

Daniel Schroeter Simião é doutor em Antropologia Social pela Universidade de Brasília e mestre em Antropologia Social pela UNICAMP, é atualmente professor adjunto do Departamento de Antropologia da Universidade de Brasília (UnB), onde atua na graduação em ciências sociais e no Programa de Pós-Graduação em Antropologia Social. Realiza pesquisas nas áreas de antropologia urbana, gênero, antrpologia do direito e da política, possuindo diversos artigos publicados nas áreas, uma coletânea organizada, além de diversos capítulos de livros no Brasil e no exterior. Integra o Instituto de Estudos Comparados em Administração Institucional de Conflitos (INCT/InEAC) e mantém colaboraão com o Núcleo de Estudos de Populações Tradicionais e Quilombolas (NuQ) da Universidade Federal de Minas Gerais. 


\section{Notas}

1. O artigo resulta de pesquisa apoiada pelo $\mathrm{CNPq}$ por meio do projeto "Gênero, Justiça e Violência: dilemas de cidadania em perspectiva comparada” (Edital Universal 14/2013). Registre-se a fundamental contribuição do INCT-InEAC - Instituto de Estudos Comparados em Administração Institucional de Conflitos, por meio de apoio financeiro e de espaço de constante interlocução.

2. A experiência, iniciativa do juiz titular daquele juizado, envolve um atendimento prévio à audiência judicial feito por uma equipe multidisciplinar, com o objetivo de construir uma escuta adequada das demandas e narrativas envolvidas no conflito, levando, em muitos casos, a soluções mediadas de problemas subjacentes à agressão em si (Simião et al., 2013).

3. Para Cardoso de Oliveira, o mundo cívico — espaço próprio do tratamento igualitário — no Brasil não é conformado ao ponto de deixar claros aos cidadãos os limites de demandas de tratamento diferenciado socialmente aceitas, que não sejam vistas como privilégio indevido ou abuso de prerrogativas. Não teríamos aqui parâmetros universalmente compartilhados para avaliar em que circunstâncias a regra universal poderia ser legitimamente flexibilizada, o que geraria conflitos constantes entre atores que interpretam diferentemente a atitude de um ou outro.

4. As autoridades locais gostavam de citar o artigo 72 da Constituição timorense, que fala sobre o poder local. Embora não dê substancialmente poder a essas figuras, o artigo é usado por elas para legitimar o que fazem, em conjunto com o artigo $2^{\circ}$ da Constituição, que diz, em seu inciso IV: "o Estado reconhece e valoriza as normas e os usos costumeiros de Timor-Leste que não contrariem a Constituição e a legislação que trate especialmente do direito costumeiro". Vale dizer que tal legislação ainda não existe. De fato, o que abriga legalmente a autoridade dos chefes de suku e de aldeia é o Decreto-Lei no 5/2004, que define as atribuições e os poderes das chamadas "autoridades comunitárias". O decreto prevê, entre as competências dos chefes de suku, "favorecer a criação de estruturas de base para a resolução e composição de pequenos conflitos que envolvam duas ou mais aldeias do suku" (artigo $3^{\circ}$, alínea d). Já para os chefes de aldeia, prevê-se, entre outras competências, "favorecer a criação de estruturas de base para composição e resolução de pequenos conflitos que surjam no seio da aldeia” (artigo $8^{\circ}$, alínea d).

5. A primeira coisa que o chefe de suku fazia, ao iniciar um evento destes, era apontar para um exemplar do Código Penal e da Constituição, à vista de todos, e dizer que se estava a iniciar um evento oficial, sendo aquele um espaço do Estado, a ser regido por tais códigos legais — embora na prática nunca o fosse, até porque nenhum dos presentes sequer havia lido o Código Penal, incluídos aí os responsáveis por propor deliberações sobre 
o conflito (os lia na'in). A presença dos códigos estatais tinha uma função mais "indéxica” do que referencial: eles simbolizavam a presença do Estado.

6. A abundância de aspas neste parágrafo se justifica pelo fato de me referir ao Estado e à cultura não como categorias analíticas das ciências sociais, mas como categorias nativas, utilizadas por atores sociais (na aldeia e nos órgãos estatais) ciosos por delimitar e defender seus espaços de ação sobre outros. Para melhor compreensão dos elementos que operam na construção dessa perspectiva, ver Silva e Simião (2012).

7. Mutin ho Mean (literalmente, branco e vermelho) faz referência aos discos de prata (belak mutin) e de ouro (belak mean) que, no passado, deviam ser oferecidos aos lia'nain pelas partes em litígio. Tem, atualmente, o sentido de penalidade às partes por terem quebrado alguma regra de conduta da aldeia. Atualmente os discos foram permutados em dinheiro, valendo USD 12.00 um disco de ouro e USD 8.00 um disco de prata. Um mutin ho mean, portanto, significa uma penalidade no valor de vinte dólares. A depender do caso, é comum que uma parte tenha que pagar de três a cinco mutin ho mean aos lia na'in (em mediações familiares) ou à aldeia ou suku (em julgamentos feitos sob os auspícios do chefe de aldeia ou de suku).

8. Os casamentos estabelecem, em Timor-Leste, uma relação muito particular entre as casas do noivo e da noiva, que deve perdurar por gerações. O grupo tomador de mulher (identificado como manefoum) assume uma série de obrigações para com o grupo doador de mulher (identificado como umane). A relação umane-manefoum estabelece uma gramática a ser usada em inúmeras circunstâncias para prescrever as trocas de bens entre os grupos. Em situações de resolução de disputa, ela é quase sempre central. Para mais detalhes sobre tal relação e as disputas de significado por ela engendrados, ver Silva (2010).

9. A ênfase no sentido dos bens trocados como constitutivo das pessoas é bem trabalhada por Kelly Silva, a quem devo muitas das observações sobre o tema, feitas em comunicação pessoal, incluindo a observação nada trivial acerca da homonímia entre o hau de Mauss e o eu em tétum.

10. Tais cerimônias de reconciliação são usualmente referidas como paz ho dame, literalmente "paz e paz”. A repetição da palavra em um par ("paz”, do português, e "dame”, do tétum) expressa a importância do paralelismo semântico na região, como já apontado por Fox (1988), acrescida da grande habilidade timorense em incorporar palavras e modelos estrangeiros em uma lógica local.

11. Exemplos etnográficos desse tipo de situação são abundantes. Para alguns, envolvendo conflitos em relações de vizinhança, e mesmo em litígios com o Estado, ver Oliveira (2005) e Simião et al. (2010).

12. Refiro-me aqui a "insulto" e "indignação" como sentimentos interligados, tal como elaborado por Cardoso de Oliveira (2002). Em diversas situações, a observação de alguém 
sendo submetido a um insulto moral gera, em quem observa de fora o evento e compartilha seus elemento simbólicos, o sentimento de indignação.

13. Devo à observação perspicaz de Marco Martínez, em comunicação pessoal, a relação com as heroínas de óperas românticas. Para mais detalhes de como o amor romântico se constituiu em sentimento legítimo na construção da modernidade europeia, ver Giddens (1993) e Viveiros de Castro e Araújo (1977).

14. Sobre a força de processos de individuação patrocinados pelo Estado e por organismos internacionais em Timor-Leste, ver Simião (2005a).

15. Digo isso por levar a sério os relatos do pai da jovem acerca de sua queixa constante sobre a escolha do pato durante a semana que antecedeu a cerimônia de reconciliação.

16. Como não presenciei o processo que definiu as multas no caso de Arminda, não sei até que ponto houve divergência entre os cinco lia na'in em relação à escolha do animal a ser sacrificado. É possível que essa não tenha sido uma decisão consensual, o que reforçaria a observação acerca da inexistência de um universo plenamente compartilhado de normas no mundo cívico da aldeia.

17. Refiro-me aqui ao caso apresentado no texto de 2011, em que a jovem I., vítima de estupro em uma aldeia, tem seu caso levado ao tribunal distrital de Díli. Ao final do processo, embora os acusados tenham sido presos, a jovem acaba expulsa de sua aldeia, tendo que buscar abrigo em uma organização de apoio a meninas vítimas de violência sexual em Díli (Simião, 2011).

18. Nesse sentido, a experiência que temos observado no Distrito Federal (Simião et al., 2013) é interessante por abrir um espaço prévio à audiência judicial. Nesse espaço, é possível a argumentação e a busca do convencimento das mulheres acerca dos riscos envolvidos em seu relacionamento, tais como percebidos pela ótica dos profissionais do atendimento.

19. Ver, por exemplo, a descrição do SOS Mulher, de São Paulo, ao longo dos anos 1980, nos trabalhos de Pontes (1986) e Gregori (1993).

20. Quando perguntamos a nossos interlocutores o sentido de uma ação ou regra em Timor-Leste, é comum ouvir como resposta a frase "Ne'e, konforme, senhor" (isso depende, senhor).

21. Entendo que, em qualquer sociedade (e em Timor-Leste não seria diferente), categorias de gênero não operam sozinhas nem de modo homogêneo na construção de subjetividades. Certamente há, em Timor-Leste, mulheres para quem sua "dignidade" independe das estruturas de casa ou dos valores predominantes no mundo cívico da aldeia. Lembro-me de tia Rosa, senhora de seus 40 anos que trabalhava em nossa casa, em Díli, originária de Oecussi, o distrito mais isolado de Timor-Leste. Tia Rosa decidira migrar para a capital sozinha, após a morte do marido, por não concordar com o modo como passaria a ser tratada em sua aldeia como viúva. Certamente tia Rosa não é um caso isolado, e parece-me 
um bom exemplo de que vários processos de subjetivação operam na construção de desejos e atitudes das mulheres timorenses.

22. A respeito dos limites da judicialização para o enfrentamento da violência doméstica, ver Azevedo (2008) e Rifiotis (2008).

\section{Referências bibliográficas}

AMORIM, Maria Stella. 2007. "Acesso à justiça e administração judicial da violência contra a mulher brasileira: políticas de despenalização e de penalização”. Anais do XIII Congresso da ANPEDI. Disponível em: <http://conpedi.org/manaus////arquivos/anais/campos/maria -_stella_de_amorim.pdf $>$. Acesso em: 10 ago. 2009.

AZEVEDO, Rodrigo Ghiringhelli. 2008. "Sistema penal e violência de gênero: análise sociojurídica da Lei 11.340/06”. Sociedade e Estado, 23(1):113-135.

BERGER, Peter. 1983. "On the Obsolescence of the Concept of Honor". In: Stanley Hauerwas \& Alasdair MacIntire (Org.). Revisions, Changing Perspectives in Moral Philosophy. Indiana: University of Notre Dame Press. pp.172-181.

CARDOSO DE OLIVEIRA, Luís Roberto. Direito legal e insulto moral: dilemas da cidadania no Brasil, Quebec e EUA. Rio de Janeiro: Relume Dumará, 2002.

2008. Existe violência sem agressão moral? Revista Brasileira de Ciências Sociais, 23(67). Disponível em: <http://www.scielo.br/scielo.php?script=sci_arttext\&pi$\mathrm{d}=$ S0102-69092008000200010\&lng $=$ en\&nrm $=$ iso >. Acesso em: 24 mar. 2013.

2010. Concepções de igualdade e (des)igualdades no Brasil. In: Roberto Kant de Lima, Lucía Eilbaum \& Lenin Pires (Org.). Conflitos, direitos e moralidades em perspectiva comparada. Rio de Janeiro: Garamond. v. 1, pp. 19-33.

DUMONT, Louis. O individualismo. Rio de Janeiro: Rocco, 1985.

FOX, James. 1988. To Speak in Pairs: Essays on the Ritual Languages of Eastern Indonesia. Cambridge: Cambridge University Press.

GEERTZ, Clifford. 1983. "Local Knowledge: Fact and Law in Comparative Perspective". In: . Local Knowledge: Further Essays in Interpretative Anthropology. New York: Basic Books. pp. 167-234.

GIDDENS, Anthony. 1993. A transformação da intimidade: sexualidade, amor e erotismo nas sociedades modernas. São Paulo: UNESP. 
GREGORI, Maria Filomena. 1993. Cenas e queixas: um estudo sobre mulheres, relações violentas e a prática feminista. Rio de Janeiro: Paz e Terra.

HOHE, Tanja \& NIXON, Rod. 2003. Reconciling Justice: 'Traditional' Law and State Judiciary in East Timor. [s.1.]: United States Institute of Peace. Mimeo.

HONNETH, Axel. 1996. The Struggle for Recognition, the Moral Grammar of Social Conflicts. Cambridge, Mass.: The MIT Press.

KANT DE LIMA, Roberto. Ensaios de antropologia e de direito: acesso à justiça e processos institucionais de administração de conflitos e produção da verdade jurídica em uma perspectiva comparada. Rio de Janeiro: Lumen Juris, 2008.

MAUSS, Marcel. 1974. Ensaio sobre a dádiva: forma e razão da troca nas sociedades arcaicas. In: . Sociologia e antropologia. São Paulo: Edusp. v. II, pp. 37-184.

OLIVEIRA, Carlos Gomes de. 2005. Saber calar, saber conduzir a oração: a administração de conflitos num Juizado Especial Criminal do DF. Dissertação de mestrado, Universidade de Brasília.

PASINATO, Wania. 2004. "Delegacias de Defesa da Mulher e Juizados Especiais Criminais: mulheres, violência e acesso à justiça”. In: XXVIII Encontro da Associação Nacional de Pós-Graduação em Ciências Sociais - ANPOCS.

PONTES, Heloísa A. 1986. Do palco aos bastidores. Dissertação de mestrado, Unicamp.

RIFIOTIS, Teophilos. 2008. "Judiciarização das relações sociais e estratégias de reconhecimento: repensando a 'violência conjugal' e a 'violência intrafamiliar'. Revista Katálysis, $11(2): 225-236$.

ROQUE, Ricardo. 2011. "Etnografias coloniais, tecnologias miméticas: usos e costumes em Timor-Leste". In: Kelly Silva \& Lucio Sousa (eds.). Ita Maun Alin: o livro do irmão mais novo. Lisboa: Colibri. pp. 155-168.

SILVA, Kelly. 2010. "Riqueza ou preço da noiva? Regimes morais em disputa nas negociações de casamento entre elites urbanas timorenses". In: Wilson Trajano Filho (org.). Lugares, pessoas e grupos: as lógicas do pertencimento em perspectiva comparada. Brasília: Athalaia. pp. 207-223. 
SILVA, Kelly \& SIMIÃO, Daniel. 2012. "Coping with 'Traditions': the Analysis of East-Timorese Nation Building from the Perspective of a Certain Anthropology Made in Brazil”. Vibrant, Virtual Brazilian Anthropolgy, 9(1). Disponível em: http://www.scielo.br/scielo. php?script $=$ sci_arttext\&pid $=$ S1809-43412012000100013\&lng $=$ en\&nrm $=$ iso. $\quad$ Acesso em: 25/03/2013.

SIMIÃO, Daniel S. 2005a. As donas da palavra: gênero, justiça e a invenção da violência doméstica em Timor-Leste. Tese de doutorado, Universidade de Brasília.

2005b. "O feiticeiro desencantado". Anuário Antropológico, 127-154.

2011. "Sensibilidade jurídica e diversidade cultural: dilemas timorenses em perspectiva comparada”. In: Kelly Silva \& Lucio Sousa (Org.). Ita Maun Alin: o livro do irmão mais novo. Lisboa: Colibri. pp. 113-129.

2012. Sé Mak Sala Tenkeser Selu Sala: desafios de justiça, direitos e diferenças em Timor-Leste. Documentário. cor. NTSC 36’. Brasília: IRIS. Disponível em: http://youtu.be/ CyKnw2Vgz6M?list=UU5lqS9UpEoTPzJd7FqoggFw. Acesso em: 25 mar. 2014.

SIMIÃO, Daniel S.; DUARTE, Vitor Barbosa ; CARVALHO, Natan Ferreira de; DAVIS, Pedro Gondim. 2010. "Sentidos de justiça e reconhecimento em formas extrajudiciais de resolução de conflitos em Belo Horizonte”. In: LIMA, Roberto Kant; EILBAUM, Lucia; PIRES, Lenin. (Org.). Conflitos, direitos e moralidades em perspectiva comparada. Rio de Janeiro: Garamond: pp. 221-250.

SIMIÃO, Daniel S.; CORREA, Ranna; LIMA, Davi; MATHIAS, Krislane \& CASTRO, Nicholas. 2013. "A aplicação da Lei Maria da Penha no Distrito Federal: análise uma experiência piloto de atendimento multidisciplinar”. In: III Seminário Internacional do InEAC. Niterói. Comunicação oral.

SOARES, Dionísio. 1999. "A Brief Overview of the Role of Customary Law in East Timor”. In: Simpósio sobre Timor-Leste, Indonésia e Região. Universidade Nova de Lisboa, Lisboa. Mimeo.

STRATHERN, Marilyn. "One Man and Many Men". In: Marilyn Strathern \& Maurice Godelier (orgs.). Big Men and Great Men: Personifications of Power in Melanesia. Cambridge: Cambridge University Press. pp. 197-214.

TAYLOR, Charles. 1994. “The Politics of Recognition”. In: Amy Gutmann (Org.). Multiculturalism and "the Politics of Recognition". New Jersey: Princeton University Press. pp. 225-256. 
VIVEIROS DE CASTRO, Eduardo; ARAUJO, Ricardo Benzaquem. 1977. "Romeu e Julieta e a origem do Estado". In: VELHO, Gilberto (org.). Arte e sociedade: ensaios de sociologia de arte. Rio de Janeiro: Zahar. pp. 130-169.

WAGNER, Roy. 1991. “The Fractal Person”. In: Marilyn Strathern \& Maurice Godelier (org.). Big Men and Great Men: Personifications of Power in Melanesia. Cambridge: Cambridge University Press. pp. 159-173.

WILLIAMS-VAN KLINKEN, Catharina. 2003. "Metaphors We Judge by: Mediation in Wehali”. In: International Conference on Traditional Conflict Resolution and Justice. The Asia Foundation, Díli, 27 Jun 2003. 


\section{Resumo}

O artigo discute os limites da judicialização de conflitos interpessoais para soluções que atendam a diferentes expectativas de reconhecimento, questionando em que medida a proteção mandatória de direitos de segmentos tidos como vulneráveis representaria o atendimento a demandas morais desses sujeitos. Para isso, toma-se como referência a discussão sobre formas locais de resolução de conflitos em Timor-Leste, como contraponto às formas judicializadas, em que há pouco ou nenhum espaço de escuta e mecanismos de reparação moral às partes. Com base em um caso de resolução de conflito com desfecho trágico, propõe-se que não basta o espaço de enunciação de histórias para que ocorra o sentimento de justiça e reparação. Aponta-se ainda para o papel central das práticas de compensação timorenses para dar conta da dimensão moral do conflito, estabelecendo, subsidiariamente, comparações com a sensibilidade jurídica brasileira e buscando caracterizar limites e possibilidades de formas de justiça de base comunitária e sua tensão com mecanismos de proteção de direito orientados por uma ideologia individualista.

Palavras-chave: Antropologia do direito; gênero; justiça; dádiva; Timor-Leste
The article discusses the limits of the judicialization of interpersonal conflicts facing different expectations for recognition. It questions if a mandatory protection of groups perceived as vulnerable would represent an adequate way of achieving moral demands of the subjects in conflict. It elaborates on the discussion about local forms of dispute resolution in East Timor, which are seen as opposed to formal legal processes and more receptive to moral compensation practices. Analyzing an ethnographic case with tragic consequences, the article proposes that mechanisms for hearing and repairing are not enough to ensure moral recognition. It points to the central role of compensation practices in East-Timorese forms of justice, establishing a comparative approach to the Brazilian legal sensibility and seeking to understand the limits and possibilities of community-based forms of justice.

Keywords: Anthropology of law; gender; justice; gift; East Timor 